\title{
Safety of long-acting $\beta$ agonists for the treatment of asthma: clearing the air
}

\author{
Gustavo J Rodrigo, ${ }^{1}$ José A Castro-Rodríguez ${ }^{2}$
}

${ }^{1}$ Department of Emergency, Hospital Central de las Fuerzas Armadas, Montevideo, Uruguay ${ }^{2}$ Departments of Pediatrics and Family Medicine, School of Medicine, Pontificia Universidad Católica de Chile, Santiago, Chile

\section{Correspondence to}

Gustavo J Rodrigo, Department of Emergency, Hospital Central de las Fuerzas Armadas, Av. 8 de Octubre 3020, Montevideo 11600, Uruguay: gurodrig@adinet.com.uy

Received 12 November 2010 Accepted 13 January 2011 Published Online First 21 April 2011

\section{ABSTRACT}

Concerns about the safety of long-acting $\beta 2$-agonist (LABA) therapy, has led to the appearance of multiple publications and recommendations. This review critically examines the available clinical evidence and safety requirements for LABA use. On the basis of nearly 20 systematic reviews and databases, the authors conclude that LABA monotherapy significantly increases the risk of asthma-related adverse effects. We also conclude that the use of LABAs concomitantly with inhaled corticosteroids (ICS) significantly reduces asthma hospitalisations and is not associated with lifethreatening events and asthma-related deaths, especially when concurrent use of LABAs and ICS can be reasonably assured (use of a single inhaler device). An appropriate clinical study would require an extremely large sample, making it impractical. Finally, some of the new US Food and Drug Administration (FDA) recommendations have caused confusion and do not appear to be fully evidence based. Although limited by low statistical power, the evidence supports the use of LABAs plus ICS in a single inhaler device (to increase adherence and reduce the potential use of LABA monotherapy) for all patients (not only children) with moderate to severe asthma.

\section{INTRODUCTION}

Short-acting $\beta$ agonists (SABAs) have been used for decades as bronchodilators in the treatment of both chronic and acute asthma. Their therapeutic profile has generally been good, although safety concerns have persisted since SABAs were implicated in two epidemics of asthma deaths in the 1960s and 1970s. ${ }^{1}$ The question of whether these epidemics effectively resulted from the use of SABAs has been the subject of intense and persisting controversy. The introduction of long-acting $\beta 2$ agonists (LABAs) in the 1990s was considered a major advance in bronchodilator therapy, with evidence that their use led to improved lung function and quality of life. However, concerns about the possible risks associated with LABA therapy appeared soon after its introduction, with the suggestion that regular use has the potential to reduce bronchodilator sensitivity to $\beta$ agonists, and induce tolerance to their bronchoprotective effects. ${ }^{2}$ It also became evident that patients with asthma using LABAs may be at risk of increased morbidity and mortality if the symptom control achieved with LABA use led to a discontinuation of inhaled corticosteroid (ICS) therapy. ${ }^{3}$ Contrary to previous hypotheses, recent prospective data have shown no evidence of a pharmacogenetic effect of $\beta$-receptor variation on salmeterol response. ${ }^{4}$
Given the serious concerns about the use of LABAs for asthma, the following review critically examines the available clinical evidence and the different safety requirements for the use of LABAs.

\section{CLINICAL EVIDENCE \\ The Serevent Nationwide Surveillance study}

GlaxoSmithKline (GSK, Brentford, Middlesex, UK) sponsored the Serevent Nationwide Surveillance (SNS) study in which patients with asthma were recruited throughout the UK. ${ }^{5}$ It was a randomised, double-blind study in parallel groups over 16 weeks, comparing inhaled salmeterol (50 $\mu \mathrm{g}$, twice daily) to salbutamol (200 $\mu \mathrm{g}$ four times daily). A total of 25180 patients were randomised to salmeterol and 8393 to salbutamol. The only significant difference between the two groups was the number of medical withdrawals because of asthma, which were fewer with salmeterol than with salbutamol (table 1). Approximately $70 \%$ of patients received ICS concomitantly. The investigators reported 12 deaths caused by asthma in the salmeterol group (7.1 per 10000 patients) and two in the salbutamol group (2.4 per 10000 patients). This threefold increased risk did not reach statistical significance. Because the number of events was very small, it is not possible to determine if this difference is a chance finding. Moreover, bias may have been introduced by the higher proportion of withdrawals in the salbutamol group. Finally, the authors considered that a number of deaths could have been prevented by more appropriate use of ICS.

\section{The Salmeterol Multicenter Asthma Research Trial (SMART)}

The US Food Drug Administration (FDA) required GSK to obtain additional data in a large new trial. ${ }^{6}$ This study was designed to evaluate the effects of salmeterol on respiratory and asthma-related deaths or life-threatening events. It was a multicentre, randomised, double-blind, parallel-group, placebo-controlled study conducted in the USA. Patients with asthma who were aged 12 years and over were assigned to receive either salmeterol $50 \mu \mathrm{g}$ twice daily via metered-dose inhalers or placebo for 28 weeks in addition to their usual therapy. Initially, patients were recruited via print, radio, and television advertising from 1996 to 1999 (phase 1). When recruitment decreased, the advertising campaign was stopped and patients were recruited by the study investigators from 2000 to 2003 (phase 2). However, following an interim analysis of 26355 patients, the sponsor decided to terminate the study due to preliminary findings in African Americans and difficulties in enrolment. This trial was planned for 60000 patients, or 238 
Table 1 Summary of data from the Serevent Nationwide Surveillance study (adapted from Castle et $a l^{5}$ )

\begin{tabular}{lccll}
\hline Variable & $\begin{array}{l}\text { Salmeterol } \\
(\mathbf{n}=\mathbf{1 6 7 8 7})\end{array}$ & $\begin{array}{l}\text { Salbutamol } \\
(\mathbf{n = 8 3 9 3})\end{array}$ & $\begin{array}{l}\text { Relative risk } \\
\text { (95\% Cl) }\end{array}$ & p value \\
\hline Total deaths & $54(0.31 \%)$ & $20(0.24 \%)$ & $1.35(0.81$ to 2.25$)$ & 0.25 \\
Respiratory and asthma deaths & $12(0.07 \%)$ & $2(0.02 \%)$ & $3.00(0.67$ to 13.4$)$ & 0.105 \\
Hospitalisations and life-threatening asthma & $193(1.1 \%)$ & $102(1.2)$ & $0.95(0.74$ to 1.20$)$ & 0.74 \\
Withdrawals due to asthma & $488(2.9 \%)$ & $318(3.8 \%)$ & $0.77(0.67$ to 0.88$)$ & 0.00002 \\
\hline
\end{tabular}

primary events, but was terminated when approximately half the target number of patients had been enrolled, subsequently providing 86 primary events.

Baseline ICS use was reported by $47 \%$ of the overall population, with $49 \%$ in white patients and 38\% among African-American patients. Data indicate greater disease severity at baseline among the African-American subgroup compared with white patients. For the primary endpoint, there were no significant differences between treatment groups in the number of respiratory-related deaths or life-threatening events (figure 1). However, the number of combined asthma deaths and lifethreatening events, and the number of asthma deaths alone were significantly higher in patients receiving salmeterol. There was one excess asthma death every 1318 salmeterol-treated patients (95\% CI 734 to 23666). Most asthma deaths occurred during phase 1 (13 of 16).

There were statistically significant differences among the African-American population in the primary endpoint and for one of the secondary endpoints (figure 1). Although SMARTwas not designed to assess the effect of ICS use on the endpoints, post hoc analyses showed that the number of events for the primary and all secondary endpoints was similar for patients reporting baseline use of ICS in both treatment groups (figure 1). In contrast, the number of primary and secondary outcome events for patients reporting no baseline ICS use was significantly greater in the salmeterol group compared with the placebo group.

Overall, the results of SMART have been controversial. There were differences in baseline asthma characteristics between white patients and African-American patients (lower baseline peak expiratory flow, more nocturnal symptoms, more emergency department visits and hospitalisations, and more intubations in their lifetimes among the latter group). In the previous 12 months there were higher numbers of hospitalisations and

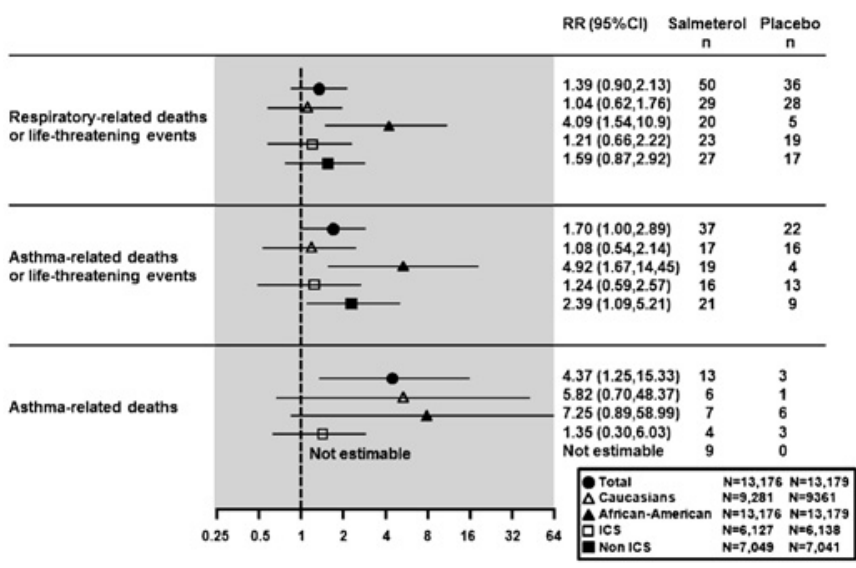

Figure 1 Pooled relative risk RR with $95 \% \mathrm{Cl}$ of primary and secondary endpoints during the 28-week study period in the Salmeterol Multicenter Asthma Research Trial (SMART) (n, number of events; N, total sample) (adapted from Nelson et $a^{6}{ }^{6}$ ). emergency department visits in the African-American patients. There were also baseline differences in the use of ICS. Finally, the finding of more deaths with salmeterol use contrasts with national statistical data in the USA on asthma deaths and prescriptions for salmeterol and salmeterol plus ICS combinations. Extrapolation of the mortality data from SMART suggests that in 2004 there would have been twofold to threefold more asthma deaths than were reported in the national statistics.

\section{Formoterol studies}

The use of formoterol was approved in the USA in a $12 \mu \mathrm{g}$ formulation based on two 12 -week studies ${ }^{7} 8$ and one 1 -year study in children aged 5-12 years. ${ }^{9}$ Clinical studies caused concern about a possible relationship between the use of higher doses $(24 \mu \mathrm{g}$ twice daily) and an increase in serious asthma exacerbations. ${ }^{10}$ As a consequence, the FDA asked the manufacturer (Novartis Pharmaceuticals Basel, Switzerland) to conduct a phase IV post-marketing clinical trial to investigate the relative safety of the two different doses of formoterol. ${ }^{11}$ This trial, which enrolled 2085 patients with stable mild-tomoderate persistent asthma (64\% received regular concomitant ICS), showed five ( $0.9 \%$ of all patients) severe asthma-related complications in the group receiving $24 \mu \mathrm{g}$ formoterol compared with two $(0.4 \%)$ in the $12 \mu$ group, and only one $(0.2 \%)$ in the placebo group, suggesting that formoterol $24 \mu \mathrm{g}$ twice daily was associated with an increase in serious asthma exacerbations. Likewise, tabular data from Novartis ${ }^{12}$ showed an increased incidence of serious asthma-related events in patients taking formoterol. Although the FDA confirmed the availability of both salmeterol and formoterol, black box warnings were required on their product labels. ${ }^{13}$

\section{The FDA meta-analysis}

This meta-analysis was in response to the recommendations from the Paediatric Advisory Committee meeting (28 November 2007) to continue assessing the risks and benefits of LABAs. ${ }^{14}$ It explored possible associations of LABAs with asthma hospitalisations, intubations, and deaths. It was based on data from 110 randomised, parallel controlled clinical trials (60954 patients) that the sponsors submitted to the FDA. The meta-analysis considered four products that contain a LABA and are approved in the USA for the treatment of asthma: salmeterol plus fluticasone, formoterol, salmeterol, and formoterol plus budesonide. The majority of patients ( $>70 \%$ of total sample) were from salmeterol trials. SMART $^{6}$ provided a substantial percentage (43\%) of the total sample. For the overall analysis, $77 \%$ of patients were aged between 18 and 64 years, 11\% between 12 and 17 years, $7 \% 65$ years and over, and only $6 \%$ between 4 and 11 years. The majority of patients were white (72\%), female $(57 \%)$, and from trials with treatment durations of 12 weeks or more (94\%).

Overall, data showed that LABAs were associated with an increased risk difference ( $R D)$ of asthma-related events relative to non-LABA treatment as measured by the asthma composite endpoint consisting of asthma deaths, asthma intubations, and 
asthma hospitalisations (figure 2). Non-LABA treatments included ICS, SABAs, other non-LABA treatments, placebo, or a combination of treatments. This overall finding was supported by a significant increase in the asthma composite endpoint, but not in the individual endpoints.

Interestingly, $\mathrm{RDs}$ for the asthma composite endpoint only increased when LABAs without randomly assigned ICS were compared with non-LABA treatment (figure 3). In contrast, the comparison of LABAs with randomised ICS versus randomised ICS alone (same ICS and dose) was not statistically significant. Three of the four products (formoterol, salmeterol, and formoterol plus budesonide) showed non-significant increases in the $\mathrm{RD}$ for the asthma composite endpoint; only salmeterol had a statistically significant estimate. There were 20 asthma-related deaths, 16 of which were in the LABA group (all occurred among salmeterol-treated patients) and four in the non-LABA group. It should be noted that the majority of trials submitted by AstraZeneca (Lund, Sweden) for the formoterol plus budesonide combination were not included in the FDA analysis (38 studies with 22240 patients) for different reasons (non-US-approved doses and age (4-11 years). ${ }^{15}$ In contrast to the FDA analysis (four trials with 1270 patients), which showed a non-significant increased risk of asthma-related hospitalisations $(\mathrm{RD}=7.49$ per 1000 patients), the analysis of the 44 trials (23510 patients) submitted by AstraZeneca showed a non-significant decreased risk ( $\mathrm{RD}=-4.5$ per 1000 patients) for formoterol plus budesonide (figure 3). There was a general trend among age, with higher $\mathrm{RD}$ among the younger age groups. RDs for all age groups, except the 65 and over age group, were positive and statistically significant. Women and African Americans showed significant increases in $\mathrm{RD}$.

In summary, LABAs were associated with an increased risk of an asthma composite endpoint. Of 44 deaths and intubations in the LABA-exposed population, 43 occurred among 22286 patients $(0.19 \%)$ in trials in which ICS use was not mandatory compared with one death among 7862 patients (0.01\%) in trials with mandatory ICS therapy. No deaths or intubations were reported for patients treated with single-device combinations of ICS and LABAs.

\section{Systematic reviews with meta-analyses based on randomised controlled trials and clinical databases}

Because of the rarity of death in asthma clinical trials, one useful approach is to analyse systematic reviews using a meta-analysis

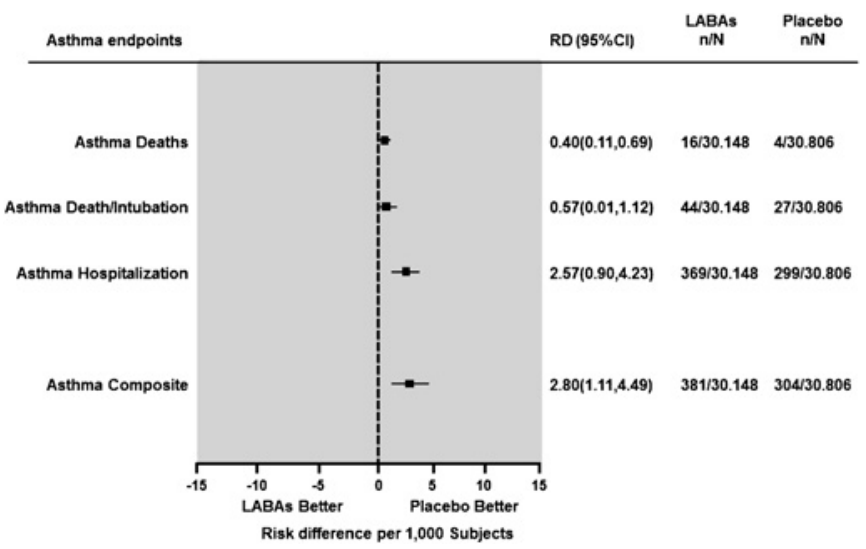

Figure 2 Pooled risk difference (RD) with $95 \% \mathrm{Cl}$ of asthma endpoints in the US Food and drug Administration (FDA) meta-analysis (n, number of events; $N$, total sample; LABAs, long-acting $\beta 2$ agonists) (adapted from Levenson ${ }^{14}$ ).

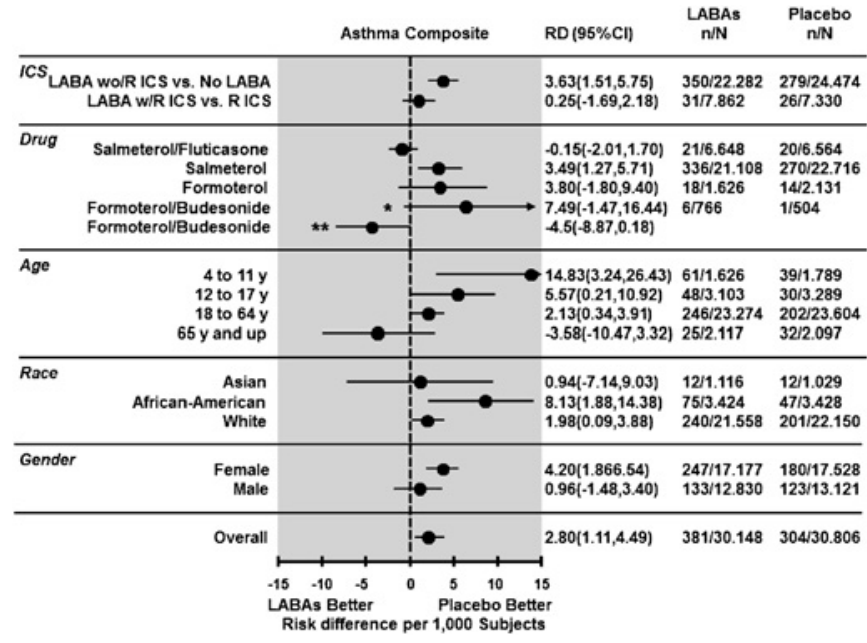

Figure 3 Pooled risk difference (RD) with $95 \% \mathrm{Cl}$ of asthma composite by subgroups in the FDA meta-analysis ( $\mathrm{n}$, number of events; $\mathrm{N}$, total sample; LABAs, long-acting $\beta 2$-agonists; LABAs wo/R ICS versus No LABAs, LABAs without randomised ICS versus no LABAs; LABAs w/R ICS versus $R$ ICS, LABAs with randomised ICS versus randomised ICS). ${ }^{*} R D$ from $4(n=1270)$ of $42(n=23510)$ studies included in the FDA analysis; ${ }^{*} \mathrm{RD}$ from $42(\mathrm{n}=23510)$ studies) (adapted from Levenson ${ }^{14}$ ).

based on randomised controlled trials (RCTs). The authors examined 16 meta-analyses: three compared LABAs with placebo, ${ }^{16-18}$ eight compared LABAs plus ICS with ICS alone, ${ }^{19-26}$ and three presented both comparisons. ${ }^{27-29}$ Additionally, we evaluated two databases of RCTs submitted by the sponsors to the FDA. ${ }^{30} 31$

Of the six reviews comparing LABAs with placebo (table 2), four $^{17} 182729$ showed significant increases in asthma deaths in the LABA group, with one excess asthma death every 1127-1824 LABA patients. The majority of deaths recorded in these reviews were from SMART. The only review that examined exclusively the effect of formotero ${ }^{16}$ presented only one asthma death in the LABA group. LABA monotherapy increased the risk of life-threatening asthma and asthma hospitalisation events, although in some reviews the effect was not statistically significant. ${ }^{17} 2729$ Clearly, analysis of these data confirms previous concerns arising from studies such as SNS or SMART. An important limitation was the low number of paediatric studies.

Reviews comparing LABAs plus ICS versus ICS alone showed quite a different picture (table 3). All reviews, except two, ${ }^{28} 29$ presented the same dose of ICS in both arms, and one included trials exclusively in children. ${ }^{22}$ Overall, asthma deaths and lifethreatening events were very rare, and patients treated with LABAs plus ICS presented a reduced risk of asthma hospitalisations. The only paediatric review ${ }^{22}$ did not show asthma deaths or life-threatening events. However, it presented a nonsignificant increased risk of asthma hospitalisations.

These findings differ markedly from the Salpeter et al review. ${ }^{28}$ These authors selected RCTs ( $\geq 3$ months) that compared LABAs with placebo or LABAs plus ICS with ICS alone. The primary outcome was catastrophic events, defined as asthmarelated intubation or death. Using data from six trials and one database provided by GSK (7253 patients), the authors concluded there was a surprisingly threefold increase in catastrophic events among patients treated with LABAs plus ICS compared with those treated with ICS alone (table 3). Nevertheless, this finding appears problematic because of different 


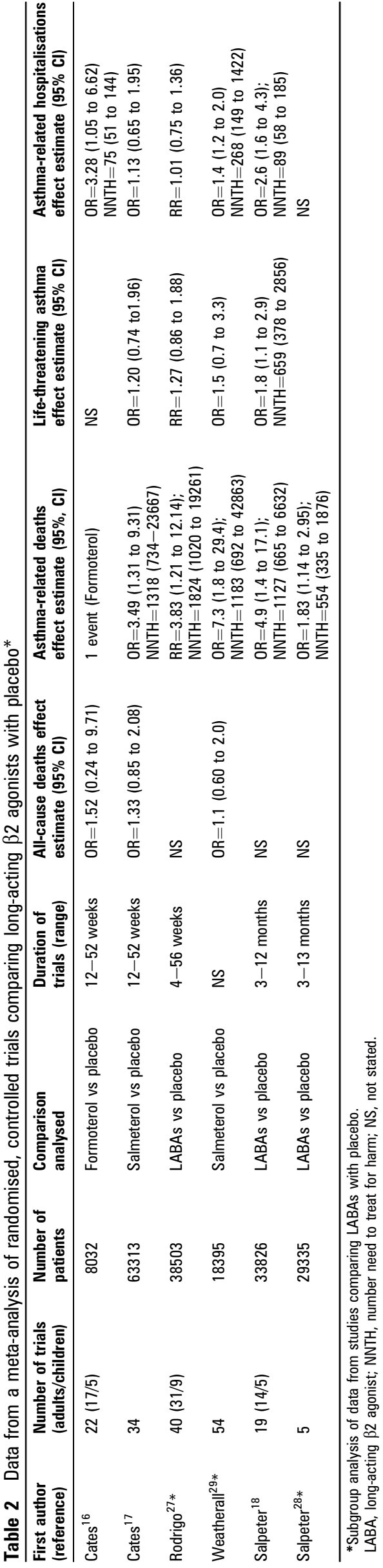

factors. Therefore, all trials included were very heterogeneous in terms of doses of ICS. Additionally, many patients received ICS as uncontrolled background treatment, and only a few studies used single inhaler devices for the combination therapy administration. Of particular interest is the GSK database of RCTs of salmeterol ${ }^{30}$ included in the Salpeter analysis. In response to an FDA request of January 2008, GSK submitted a database with a meta-analysis of 215 studies representing over 100000 patients. These data explain $57 \%$ (8 of 14) of the primary outcome events for LABA plus ICS therapy in the Salpeter review. Three clinical situations were examined during which a patient could have received ICS concurrently with salmeterol: the addition of salmeterol to background ICS (ICS were not administered as part of the protocol); salmeterol and ICS as blinded study medications administered in separate inhaler devices, as part of the study protocol; and administration of salmeterol and ICS as a blinded study medication in a single inhaler. Only the last situation assures the concurrent use of ICS each time a patient was exposed to salmeterol. Therefore, the latter population was the most accurate to inform the safety profile of salmeterol in the presence of ICS. The results showed (table 4) that for studies in which the concurrent use of salmeterol and ICS can be reasonably assured (eg, salmeterol plus ICS in a single inhaler device vs ICS), there was no evidence of increased risk for asthma deaths or intubations. In contrast, when salmeterol was used in the absence of an ICS or when the use of an ICS was not controlled (eg, salmeterol plus ICS vs ICS background or separate inhaler devices), an increase (although not significant) in serious asthma-related events was observed. A final objection to the Salpeter review is the absence of several additional published and unpublished studies that met the inclusion criteria.

AstraZeneca (Lund, Sweden) also submitted a comprehensive review to the FDA of the available data for formoterol plus budesonide metered-dose inhalers and Turbuhaler trials ( $\geq 12$ years). ${ }^{31}$ The most relevant subset of the full dataset consists of 15852 patients across 27 studies and consists of patients that received formoterol plus ICS versus ICS alone. There were no asthma-related deaths, and the FDA asthma composite endpoint (death, intubation, and hospitalisation) decreased significantly (odds ratio $(\mathrm{OR})=0.62 ; 95 \%$ CI 0.42 to 0.93 ) in patients receiving combination therapy.

A different development for combined ICS plus LABA treatment is the use of budesonide plus formoterol as both maintenance and reliever therapy (SMART strategy). ${ }^{32}$ Safety data from six double-blind RCTs (14346 patients) in which budesonide plus formoterol was used for at least 6 months showed good tolerance and no increased safety concerns, with lower or similar incidence of death and asthma-related serious adverse events compared with the fixed-dose comparators. ${ }^{33}$

Finally, the analysis of 41 AstraZeneca-sponsored RCTs ( $\geq 3$ months) $)^{34}$ showed that formoterol (82\% with concomitant ICS) as maintenance and/or as reliever therapy with almost 12000 children and adolescents was not associated with any increased risk of asthma hospitalisations. There was only one asthma death among formoterol-treated patients.

\section{ARE NEW DATA NEEDED?}

Although mortality is a very rare event in the use of LABAs with mandatory ICS trials, estimates of risk should be interpreted with caution, given that such trials were not powered on these events. Accordingly, the FDA is requiring the manufacturers of LABAs to conduct additional studies to evaluate their safety. ${ }^{35}$ Likewise, some authors ${ }^{36}{ }^{37}$ have issued a call for a very 


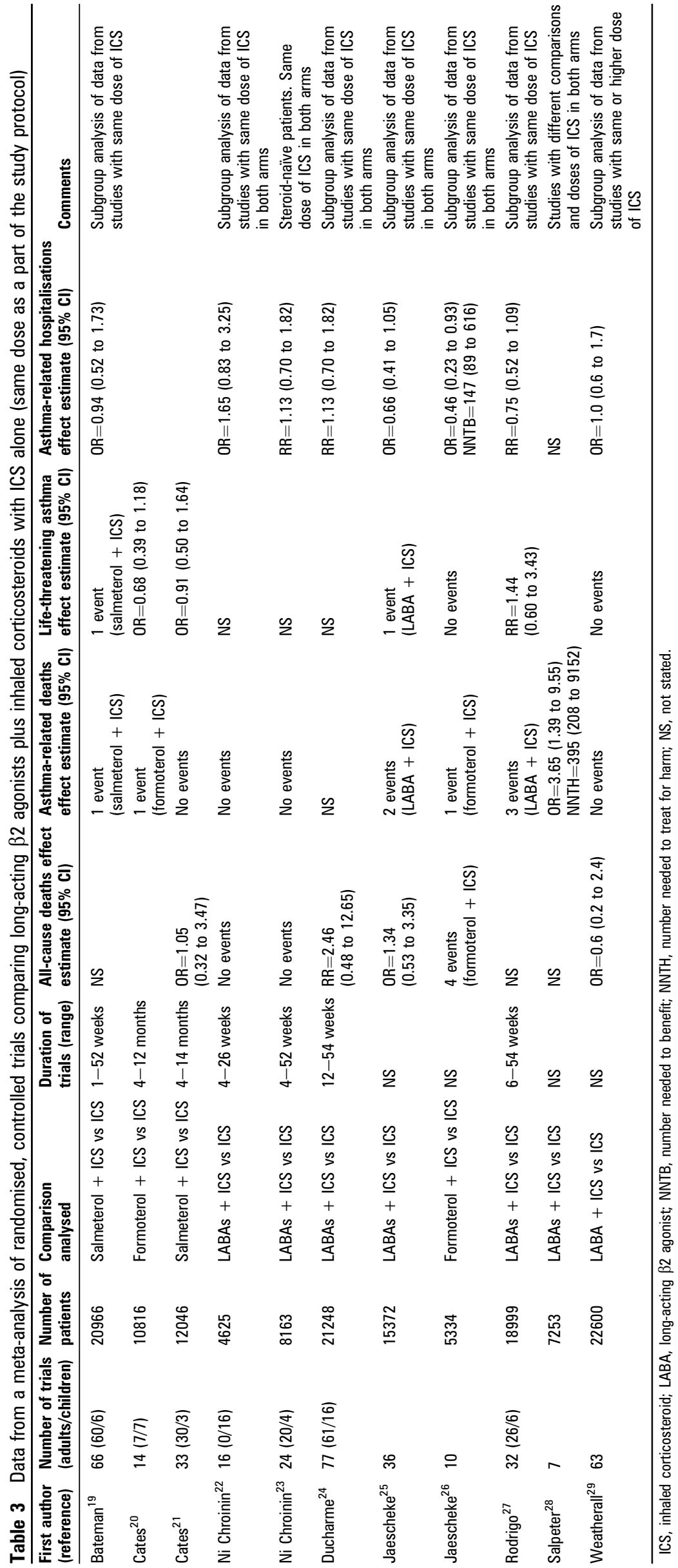


Table 4 Risk differences per 10000 patients for asthma-related deaths and intubations (adapted from GlaxoSmithKline ${ }^{30}$ )

\begin{tabular}{|c|c|c|c|c|c|c|c|c|c|c|}
\hline \multirow[b]{2}{*}{ Comparison } & \multicolumn{2}{|c|}{ Salmeterol } & \multicolumn{2}{|c|}{ Comparator } & \multirow{2}{*}{$\begin{array}{l}\text { Asthma-related deaths } \\
\text { RD (95\% Cl) }\end{array}$} & \multicolumn{2}{|c|}{ Salmeterol } & \multicolumn{2}{|c|}{ Comparator } & \multirow{2}{*}{$\begin{array}{l}\text { Asthma-related intubations } \\
\text { RD (95\% CI) }\end{array}$} \\
\hline & $\bar{n}$ & $\mathbf{N}$ & $\bar{n}$ & $\mathbf{N}$ & & $\bar{n}$ & $\mathbf{N}$ & $\bar{n}$ & $\mathbf{N}$ & \\
\hline Salmeterol vs placebo (no ICS) & 8 & 9463 & 0 & 8932 & $8.79(-8.23$ to 25.80$)$ & 15 & 9463 & 10 & 8932 & $5.42(-13.67$ to 24.52$)$ \\
\hline Salmeterol + ICS $_{\mathrm{BK}}$ vs ICS $\mathrm{BK}_{\mathrm{BK}}$ & 5 & 10264 & 3 & 10135 & $2.03(-12.17$ to 16.22$)$ & 20 & 10264 & 13 & 10135 & $7.16(-10.08$ to 24.39$)$ \\
\hline Salmeterol + ICS $_{S D}$ vs ICS & 0 & 11437 & 0 & 11163 & Not estimable & 0 & 11437 & 0 & 11163 & Not estimable \\
\hline
\end{tabular}

BK, background; ICS, inhaled corticosteroid; $n$, number of events; $N$, total sample; RD, risk difference; $S D$, single device; $S P$, separate inhaler devices.

large randomised clinical study. The appropriate next step could be to conduct an adequately powered, well designed, prospective study to define the magnitude of the risk resulting from treating patients with asthma with LABAs plus ICS versus the same dose of ICS alone. Kazani et al ${ }^{38}$ proposed that 50000 patients with moderate or severe asthma should be enrolled in a randomised double-blind trial, with half of the patients treated with ICS and the other half treated with ICS plus LABAs. Enrolled patients should be followed until 20 severe asthma episodes or asthma deaths have occurred in the entire cohort. However, this proposed study would not have the power to definitively rule out a relative risk of less than fourfold because the sample size was based on data from LABA studies that did not mandate ICS use. In contrast, Sears ${ }^{38}$ states that a large trial is neither practicable nor necessary and will not provide any more useful data about adverse asthma events than those presently available. Based on data from the FDA meta-analysis, ${ }^{14}$ Sears has estimated the large sample sizes necessary for different outcomes (table 5). The use of the FDA composite outcome of deaths, intubations and hospitalisations would introduce major difficulties in interpretation because data have shown that LABA use with concomitant randomised ICS is either neutral in risk for exacerbations (dominantly hospitalisations), or reduces risk. ${ }^{5} 23-27$ Therefore, using the composite outcome would produce results opposing those suggested by the worst-case interpretation of the mortality data.

\section{Observational studies}

With rare outcomes of treatment, such as asthma mortality, the failure of different designs to detect associations may represent type II error, and so indicate a lack of statistical power rather than the absence of an association. Researchers should very cautiously interpret evidence of safety for a rare adverse event, such as asthma death with LABA use, based on the traditional categories of evidence. It has been established that in a real scenario, meta-analyses of RCTs and single large RCTs lack statistical power to detect or rule out this association. ${ }^{39}$ Casecontrol methodology may be a better approach because it requires a smaller sample size. However, the risks of bias are higher than those of a well designed RCT, or a properly conducted meta-analysis of RCTs.

Table 5 Sample sizes calculations for a new study comparing longacting $\beta 2$ agonists plus mandatory inhaled corticosteroids versus ICS alone (adapted from Kazani ${ }^{38}$ )

\begin{tabular}{llc}
\hline Risk difference & Clinical outcomes & $\begin{array}{l}\text { Sample size } \\
\text { (number of subjects) }\end{array}$ \\
\hline $0.25 \times 1.000$ & 1 excess asthma death & 4384000 \\
$0.25 \times 1.000$ & 1 excess asthma death or intubation & 77000 \\
$0.25 \times 1.000$ & 5 excess asthma deaths or intubations & 770000 \\
$0.15 \times 1.000$ & 5 excess asthma deaths or intubations & 1200000 \\
\hline
\end{tabular}

A case-control study of 532 patients who died from asthma found an association between asthma deaths and use of SABAs in the period $1-5$ years prior to death ${ }^{40}$ without evidence of any positive association of LABAs in any period (3, 4-12 months and $1-5$ years before death). Another case-control study used the UK's General Practice Research Database (GPRD) (96258 patients) to assess respiratory mortality and found the strongest association with heavy use of SABAs. ${ }^{41}$ Lanes et al ${ }^{42}$ performed an open cohort study with a nested case-control analysis in the UK based on the GPRD (14 657 patients). The authors concluded that salmeterol use was not associated with an increase in shortterm mortality compared with the use of ipratropium and theophylline. Finally, Lang et $a l^{43}$ looked at data on asthma hospitalisations in Philadelphia from 1995 to 1999 and prescription rates for LABAs and other asthma drugs. The authors found that asthma hospitalisation was significantly associated with increased SABA prescriptions, poverty, area of residence, and African-American identity. By contrast, LABAs appeared to be protective, with lower rates of hospitalisation. However, asthma deaths are highly related to health behaviour, psychosocial factors, ${ }^{44}$ poor adherence, and the underuse of primary care services, ${ }^{45}$ and it is unlikely that sufficient information will be available in epidemiological datasets to deal completely with these biases. Finally, ecological analysis of asthma-related events and ICS dispensing observational data have shown a gradual reduction in asthma mortality in the USA since 2000, in the setting of a marked increase in LABA use predominantly in combination therapy. ${ }^{46}$

A novel approach has recently been developed to describe the patterns of hazard rates of asthma outcomes with changes in exposures. ${ }^{47}$ This pattern analysis focuses on the convergence or divergence of hazard rates rather than on estimating relative rates. The objectives of this study were to describe the patterns of risk of death and asthma outcomes with exposure to different asthma medications in general practice, and to statistically compare these patterns of risk among LABAs, inhaled SABAs and ICS. The study population included patients receiving $\beta$-agonist treatment aged 18 years and over in the UK GPRD (507966 patients), which is linked to the national registry of hospitalisations. The mortality rate increased with the least and the most severe treatment steps. Higher relative rates of outcomes were found in patients who had recently started treatment and in those receiving long-term LABA, SABA and ICS treatment. The relative death rate was statistically similar over time between LABAs and ICS despite differences in exposure. There were no statistically significant increases in the risk of death and asthma outcomes with LABAs compared with other asthma medications.

\section{FDA 2010 NEW SAFETY REQUIREMENTS FOR LABAs}

Recently, because of safety concerns and exercising new authority under the FDA Amendments Act of 2007, the FDA 
implemented new recommendations about how LABAs should be used in the treatment of asthma. ${ }^{48}$ The specific label changes were:

1. the use of LABAs without the use of an asthma controller medication such as an ICS is contraindicated (absolutely advised against) in the treatment of asthma;

2. LABAs should only be used as additional therapy for patients with asthma who are currently taking a long-term asthma control medication, such as an ICS, but whose symptoms are not adequately controlled;

3. LABAs should be used for the shortest period of time required to achieve control of asthma symptoms and then discontinued, if possible, once asthma control is achieved; patients should then be maintained on asthma controller medication;

4. paediatric and adolescent patients who require the addition of an LABA to an ICS should use a combination product containing both an ICS and a LABA to ensure adherence to both medications.

These changes are based on FDA analyses of studies showing an increased risk of severe adverse effects in paediatric and adult patients using LABAs for the treatment of asthma.

These recommendations appropriately emphasise the risk associated with the use of LABA monotherapy (largely based on findings of SNS and SMART trials ${ }^{56}$ and meta-analysis). ${ }^{12} 2729$ Also, the FDA's reminder that LABAs are not recommended as adjunct therapy in patients whose asthma is adequately controlled with low-dose ICS agrees with the National Asthma Education and Prevention Program's Expert Panel Report-3 (EPR-3) guidelines. ${ }^{49}$ However, some of the new recommendations have caused confusion and do not appear to be fully evidence based. ${ }^{50}$ For example, the change proposed by the FDA in point 3 implies that once adequate control is achieved after the addition of an LABA to ICS therapy, initial consideration should be given to stepping down therapy by discontinuing the LABA. However, the EPR- $3^{49}$ and the Global Initiative for Asthma ${ }^{51}$ guidelines recommend that care is stepped down only after asthma control is achieved and maintained for a sufficient length of time (several months). The idea of stopping LABA use 'once control is achieved' suggests a quick or sudden withdrawal of therapy (LABAs) as soon as control is achieved. We must keep in mind that the concept of asthma control includes two different domains (impairment and risk), and that medications might affect the two in different ways, particularly in patients with severe asthma. In fact, evidence suggests that stopping LABAs after the achievement of asthma control results in the patient's asthma becoming less controlled. ${ }^{52}$ Recently, Reddel et $a l^{53}$ showed that patients with well controlled asthma who are taking high doses of ICS plus LABAs can safely reduce the ICS dose to levels that are lower than advisable with ICS alone, without loss of asthma control or evidence of disease activity.

The FDA's recommendation against LABA use in patients whose asthma is controlled with a low-medium dose of ICS is also controversial. Therefore, the EPR- $3^{49}$ considers the choice of either increasing the dose of an ICS or adding a LABA as equal options for preferred step-up therapy. This recommendation is the result of weighing the benefits of combining LABAs and lowdose ICS therapy and the infrequent risk of serious adverse events. In effect, there is a large body of evidence that supports the superior effectiveness of adding LABAs to low-dose ICSs rather than increasing the dose of ICSs, even in preschoolers and school children with moderate to severe asthma, and in adults with asthma. ${ }^{54}{ }^{55}$ Finally, it is difficult to understand why the FDA recommended the use of combination products in a single device only in children and adolescents. The difficulty of ensuring compliance might apply to all age groups. Actually, there are no data to indicate a higher risk exclusively in the paediatric population. Compliance to treatment is a crucial issue of the therapeutic process that can increase the risk of serious adverse effects. It has been suggested that adherence profiles of ICS plus LABAs in a single inhaler are significantly better when compared with the controller regimens in separate inhalers. ${ }^{56}$

\section{CONCLUSIONS}

Based mainly on the safety concerns arising from the SNS and SMART $^{5}{ }^{6}$ studies, some authors have suggested withdrawing LABA use for asthma therapy. However, these serious events have been infrequent and appeared when LABAs were used as monotherapy. By contrast, evidence from RCTs, meta-analysis of RCTs and observational studies, although limited by low statistical power, have indicated that the use of combination therapy (LABAs plus ICS) is associated with a decreased risk of serious asthma-related events. This is particularly true when the concomitant use of LABAs plus ICS can be reasonably assured (combined in a single inhaler). Therefore, the use of separate inhalers could result in periods of LABA monotherapy because of poor compliance with ICS use. Combination therapy could reduce asthma mortality by increasing the prescription and increasing compliance with ICS in the community. Furthermore, combination therapy should be applied to all patients with moderate to severe asthma, and not just paediatric and adolescent patients, as suggested by the FDA guidelines.

Funding This study came from salary support for Drs Rodrigo and Castro-Rodriguez.

Competing interests In the past 3 years, GJR has received compensation for participating as a lecturer and speaker in scientific meetings and courses under the sponsorship of Boehringer Ingelheim, GlaxoSmithKline, AstraZeneca, Dr Esteve SA and Merck Sharp \& Dome, and received a consulting fee from Almirall. JCR received compensation for participating as a lecturer and speaker in scientific meetings and courses under the sponsorship of Merck Sharp \& Dohme, GlaxoSmithKline and AstraZeneca.

Provenance and peer review Not commissioned; externally peer reviewed.

\section{REFERENCES}

1. Tattersfield $\mathbf{A E}$. Current issues with $\beta_{2}$-adrenoceptor agonists. Historical background. Clin Rev Allergy Immunol 2006;31:107-17.

2. Cheung D, Timmers MC, Zwinderman $\mathrm{AH}$, et al. Long-term effects of a long-acting $\beta 2$-adrenoceptor agonist, salmeterol, on airway hyperresponsivenessin patients with mild asthma. N Engl J Med 1992;327:1198-1203.

3. Arvidsson P, Larsson S, Lofdahl CG, et al. Inhaled formoterol during one year in asthma: a comparison with salbutamol. Eur Respir J 1991;4:1168-73.

4. Bleecker ER, Nelson HS, Kraft M, et al. $\beta_{2}$-receptor polymorphisms in patients receiving salmeterol with or without fluticasone propionate. Am J Respir Crit Care Med 2010;181:676-87.

5. Castle W, Fuller R, Hall J, et al. Serevent nationwide surveillance study: comparison of salmeterol with salbutamol in asthmatic patients who require regular bronchodilator treatment. BMJ 1993;306:1034-7.

6. Nelson HS, Weiss ST, Bleecker ER, et al. The salmeterol multicenter asthma research trial. A comparison of usual pharmacotherapy for asthma or usual pharmacotherapy plus salmeterol. Chest 2006;129:15-26.

7. FitzGerald JM, Chapman KR, Della Cioppa G, et al. Sustained bronchoprotection bronchodilatation, and symptom control during regular formoterol use in asthma of moderate or greater severity. The Canadian F0/OD1 Study Group. J Allergy Clin Immunol 1999;103:427-35.

8. Bensch G, Lapidus RJ, Levine BE, et al. A randomized, 12-week, double-blind, placebo controlled study comparing formoterol dry powder inhaler with albuterol metered-dose inhaler. Ann Allergy Asthma Immunol 2001;86:19-27.

9. Bensch G, Berger WE, Blokhin BM, et al. International study group on foradil evaluation in pediatric asthma. One-year efficacy and safety of inhaled formoterol dry powder in children with persistent asthma. Ann Allergy Asthma Immunol 2002;89:180-90.

10. Mann M, Chowdhury B, Sullivan E, et al. Serious asthma exacerbations in asthmatics treated with high-dose formoterol. Chest 2003;124:70-4.

11. Wolfe J, Laforce C, Friedman B, et al. Formoterol, $24 \mu \mathrm{g}$ bid, and serious asthma exacerbations: similar rates compared with formoterol, $12 \mu \mathrm{g}$ bid, with and without extra doses taken on demand, and placebo. Chest 2006;129:27-38. 
12. Novartis. Sponsor briefing information. http://www.fda.gov/ohrms/dockets/ac/08/ briefing/2008-4398b1-02-Novartis.pdf (accessed 20 Oct 2010)

13. Food and Drug Administration Center for Drug Evaluation and Research. Summary minutes of the Pulmonary-Allergy Drugs Advisory Committee. http://www.fda. gov/ohrms/dockets/ac/05/minutes/2005-4148M1_Final.pdf (accessed 24 Sep 2010).

14. Levenson M. Long-acting beta-agonists and adverse asthma events meta-analysis: statistical briefing package for joint meeting of the Pulmonary-Allergy Drugs Advisory Committee, Drug Safety and Risk Management Advisory Committee, and Pediatric Advisory Committee on December 10-11, 2008. http://www.fda.gov/ohrms/ dockets/ac/08/briefing/2008-4398b1-01-FDA.pdf. (accessed 24 0ct 2010).

15. Nelson H, Bonuccelli C, Radner F, et al. Safety of formoterol in patients with asthma: combined analysis of data from double-blind, randomized controlled trials. J Allergy Clin Immunol 2010;125:390-6.

16. Cates CJ, Cates MJ, Lasserson TJ. Regular treatment with formoterol for chronic asthma: serious adverse events. Cochrane Database Syst Rev 2008;(4):CD006923. doi:10.1002/14651858.CD006923.pub2.

17. Cates CJ, Cates MJ. Regular treatment with salmeterol for chronic asthma: serious adverse events. Cochrane Database Syst Rev 2008;(3):CD006363. doi:10.1002/ 14651858.CD006363.pub2.

18. Salpeter SR, Buckley NS, Ormiston TM, et al. Meta-analysis: effect of long-acting $\beta$-agonists on severe asthma exacerbations and asthma-related deaths. Ann Intern Med 2006;144:904-12.

19. Bateman E, Nelson H, Bousquet J, et al. Meta-analysis: Effects of adding salmeterol to inhaled corticosteroids on serious asthma-related events. Ann Intern Med 2008;149:33-42.

20. Cates $\mathbf{C J}$, Lasserson TJ, Jaeschke R. Regular treatmentwith formoterol and inhaled steroids for chronic asthma: serious adverse events. Cochrane Database Syst Rev 2009:(2):CD006924. doi:10.1002/14651858.CD006924.pub2

21. Cates CJ, Lasserson TJ, Jaeschke R. Regular treatment with salmeterol and inhaled steroids for chronic asthma: serious adverse events. Cochrane Database Syst Rev 2009;(3):CD006922. doi:10.1002/14651858.CD006922.pub2.

22. Ni Chroinin M, Lasserson TJ, Greenstone I, et al. Addition of long-acting betaagonists to inhaled corticosteroids for chronic asthma in children. Cochrane Database Syst Rev 2009;(3):CD007949. doi:10.1002/14651858.CD007949.

23. Ni Chroinin M, Greenstone I, Lasserson TJ, et al. Addition of long-acting beta2agonists to inhaled steroids as first line therapy for persistent asthma in steroid-naive adults and children. Cochrane Database Syst Rev 2009;(4):CD005307. doi:10.1002/ 14651858.CD005307.pub2.

24. Ducharme FM, NiChroinin M, Greenstone I, et al. Addition of long-acting beta2agonists to inhaled corticosteroids versus same dose inhaled corticosteroids for chronic asthma in adults and children. Cochrane Database Syst Rev 2010;(5):CD005535. doi:10.1002/14651858.CD005535.pub2.

25. Jaeschke R, O'Byrne1 PM, Mejza F, et al. The safety of long-acting $\beta$-agonists among patients with asthma using inhaled corticosteroids. Systematic review and meta-analysis. Am J Respir Crit Care Med 2008;178:1009-16.

26. Jaeschke R, O'Byrne PO, Nair P, et al. The safety of formoterol among patients with asthma using inhaled corticosteroids. Systematic review and meta-analysis. Pol Arch Med Wewn 2008;118:627-34.

27. Rodrigo GJ, Moral VP, Marcos LG, et al. Safety of regular use of long-acting beta agonists as monotherapy or added to inhaled corticosteroids in asthma. A systematic review. Pulm Pharmacol Ther 2009;22:9-19.

28. Salpeter SR, Wall AJ, Buckley NS. Long-acting beta-agonists with and without inhaled corticosteroids and catastrophic asthma events. Am J Med 2010;123:322-8.

29. Weatherall $\mathbf{M}$, Wijesinghe $\mathbf{M}$, Perrin $\mathrm{K}$, et al. Meta-analysis of the risk of mortality with inhaled corticosteroid therapy salmeterol and the effect of concomitant. Thorax 2010;65:39-43.

30. GlaxoSmithKline. Sponsor briefing information. Benefit risk assessmentof salmeterol for the treatment of asthma in adults and children. http://www.fda.gov/ ohrms/dockets/ac/08/briefing/2008-4398b1-04-GSK.pdf (accessed 16 0ct 2010).

31. AstraZeneca. Symbicort (budesonide/formoterol) inhalation aerosol. Briefing document: design and feasibility assessments for a post-marketing safety study. http://www.fda.gov/downloads/AdvisoryCommittees/CommitteesMeetingMaterials/ Drugs/Pulmonary-AllergyDrugsAdvisoryCommittee/UCM202706.pdf laccessed 15 Oct 2010).
32. Chapman KR, Barnes NC, Greening AP, et al. Single maintenance and reliever therapy (SMART) of asthma: a critical appraisal. Thorax 2010;65:747-52.

33. Sears R, Radner F. Safety of budesonide/formoterol maintenance and reliever therapy in asthma trials. Respir Med 2009;103:1960-8.

34. Price JF, Radner F, Lenney W, et al. Safety of formoterol in children and adolescents: experience from asthma clinical trials. Arch Dis Child 2010;95:1047-53.

35. U.S. FDA Drug Safety Communication. New safety requirements for long-acting inhaled asthma medications called long-acting beta-agonists (LABAs). 2010. http://www. fda.gov/Drugs/DrugSafety/PostmarketDrugSafetylnformationforPatientsandProviders/ ucm200776.htm (accessed 15 Oct 2010).

36. Martinez FD. Safety of long-acting beta-agonists. An urgent need to clear the air N Engl J Med 2005;353:2637-9.

37. Drazen JM, O'Byrne PM. Risks of long-acting beta-agonists in achieving asthma control. N Engl J Med 2009;360:1671-2.

38. Kazani S, Ware JH, Drazen JM, et al. The safety of long-acting beta-agonists: more evidence is needed. Respirology 2010:15:881-6.

39. Weatherall M, Wijesinghe M, Perrin K, et al. Long-acting beta-agonists and asthma death: how useful are different. Study designs to evaluate the potential association? J Asthma 2010;47:434-8.

40. Anderson HR, Ayres JG, Sturdy PM, et al. Bronchodilator treatment and deaths from asthma: case-control study. BMJ 2005;330:117.

41. Lanes SF, Garcia Rodriguez LA, Huerta C. Respiratory medications and risk of asthma death. Thorax 2002;57:683-6.

42. Meier $\mathbf{C R}$, Jick $\mathrm{H}$. Drug use and pulmonary death rates in increasingly symptomatic asthma patients in the U.K. Thorax 1997;52:612-17.

43. Lang DM, Polansky M, Sherman MS. Hospitalizations for asthma in an urban population: 1995-1995. Ann Allergy Asthma Immunol 2009:103:128-33.

44. Ernst P, Mclvor A, Ducharme FM, et al. Canadian Asthma Guideline Group. Safety and effectiveness of long-acting inhaled beta-agonist bronchodilators when taken with inhaled corticosteroids. Ann Intern Med 2006:145:692-4.

45. Williams LK, Pladevall M, Xi H, et al. Relationship between adherence to inhaled corticosteroids and poor outcomes among adults with asthma. J Allergy Clin Immunol 2004:114:1288-93.

46. DiSantostefano RL, Davis KJ, Yancey S, et al. Ecologic analysis of asthma-related events and dispensing of inhaled corticosteroid- and salmeterol-containing products. Ann Allergy Asthma Immunol 2008;100:558-60.

47. de Vries F, Setakis E, Zhang B, et al. Long-acting beta2-agonists in adult asthma and the pattern of risk of death and severe asthma outcomes: a study using the GPRD. Eur Respir J 2010;36:494-502.

48. Chowdhury BA, Dal Pan G. The FDA and safe use of long-acting beta-agonists in the treatment of asthma. N Engl J Med 2010:362:1169-71.

49. NAEPP3 Science base committee. Expert Panel Report 3 (EPR-3): guidelines for the diagnosis and management of asthma-summary report 2007. J Allergy Clin Immunol 2007:120(5 Suppl):S94-138.

50. Lemanske RF, Busse WW. The US Food and Drug Administration and long-acting 32-agonists: the importance of striking the right balance between risks and benefits of therapy? J Allergy Clin Immunol 2010;126:449-52.

51. Global Initiative for Asthma, National Heart, Lung, and Blood Institute. Global Strategy for Asthma Management and Prevention. http://www.ginasthma.com/ laccessed 28 Sep 2010).

52. Koenig SM, Ostrom N, Pearlman D, et al. Deterioration in asthma control when subjects receiving fluticasone propionate/salmeterol 100/50 mcg Diskus are 'stepped-down'. J Asthma 2008;45:681-7.

53. Reddel HK, Gibson PG, Peters MJ, et al. Down-titration from high-dose combination therapy in asthma: removal of long-acting beta2-agonist. Respir Med 2010;104:1110-20

54. Gappa M, Zachgo W, von Berg A, et al. Add-on salmeterol compared to double dose fluticasone in pediatric asthma: a double-blind, randomized trial (VIAPAED). Pediatr Pulmonol 2009;44:1132-42.

55. Murray CS, Custovic A, Lowe LA, et al. Effect of addition of salmeterol versus doubling the dose of fluticasone propionate on specific airway resistance in children with asthma. Allergy Asthma Proc 2010;31:415-21.

56. Stempel DA, Stoloff SW, Carranza Rosenzweig JR, et al. Adherence to asthma medication regimens. Respir Med 2005;10:1263-7. 